\title{
PSYCHOMETRIC PROPERTIES OF THE GEORGIAN VERSION OF THE GRIT SCALE
}

Natalia SORDIA, PhD.C.(D1*

Prof. Asoc. Dr. Khatuna MARTSKVISHVILI

1 Ivane Javakhishvili Tbilisi State University, Tbilisi, Georgia; Department of Psychology, Faculty of Psychology and Educational Science, natia.sordia900@pes.tsu.edu.ge, *Corresponding Author

2Ivane Javakhishvili Tbilisi State University, Tbilisi, Georgia; Department of Psychology, Faculty of Psychology and Educational Sciences

\section{Article history:}

Accepted 21 November 2019 Available online 31 April 2020

\section{Keywords:}

Grit,

Personality traits,

Creative activities,

Creative achievements,

Psychological well-being.

\begin{abstract}
A b s t r a c t
The concept of grit refers to an individual's tendency to keep perseverance and passion for long-term goals despite setbacks or obstacles. The present research examines the psychometric properties of the Georgian version of the Grit. 431 individuals participated in the study. Results from the confirmatory factor analyses (CFA) supported a two-dimensional higher-order structure of grit. The relationship with big five personality traits, creative activities, creative achievements, and psychological well-being demonstrated the construct validity of the Georgian version of the Grit Scale (G-Grit). The Georgian version of the Grit Scale seems well suited for future research purposes.
\end{abstract}

\section{Literature Review}

Why do some individuals accomplish more than others with equal intelligence? To answer this question Duckworth and colleagues (2007) introduced the concept of grit as a higher-order personality trait expressed in perseverance and passion for long-term goals (Duckworth, Peterson, Matthews, \& Kelly, 2007). One of the factors of grit - consistency of interests - reflects an individual's tendency to maintain focus on the accomplishment of the personally meaningful goals for a long period of time. People with high scores on another factor of grit - perseverance of effort - pursue those goals with sustained effort despite setbacks or obstacles (Duckwort et al., 2007; Duckworth \& Gross, 2014). Those with high scores on grit make fewer career changes, than less gritty individuals; the overall score of grit might increase over the life span as older individuals tend to be higher in grit, then younger ones (Duckworth, Peterson, Matthews, \& Kelly, 2007).

Grit is considered to be more than just one of the big five personality traits (namely, conscientiousness), as it entails the capacity to sustain both, effort and interest in long-term projects (Duckworth, Peterson, Matthews, \& Kelly, 2007). However, besides the similarity between the definitions of grit, on the one hand, and conscientiousness, on the other hand, recent metaanalysis (Credé, Tynan, \& Harms, 2017) demonstrate that the relations of grit and its factors to conscientiousness is very strong and positive. Emotional stability and self-control (often addressed as one of the facets of conscientiousness) are strong positive correlates of grit as well (Credé et al., 2017). Agreeableness and extraversion are positively related to both of the factors as well as the overall score of grit, while perseverance of effort solely correlates with openness to experience (Butz, Hanson, Schultz, \& Warzynski, 2018; Duckworth et al., 2009). Beyond the talent that is necessary for being successful in a particular domain, the gritty individuals are most likely to engage in the amount of deliberate practice that is required for having a good performance (Duckworth, Kirby, Tsukayama, Berstein, \& Ericsson, 2011). Grit is considered to be a significant predictor of a performance on well-defined tasks, but not on ill-defined ones, where creativity and the readiness to give up unsuccessful strategies is required (Credé, Tynan, \& Harms, 2016).

General score of grit is positively related with performance and success in domains of sport (Larkin, O’Connor, \& Williams, 2015), military services, sales, academic and everyday life (Eskreis-winkler, Duckworth, Shulman, \& Beal, 2014; Credé et 
al., 2017; Duckworth et al., 2007). However, the latest studies aimed to examine whether grit is a domain specific or domain general personality trait, have demonstrated mixed results supporting both domain specificity and domain generality of grit (Cormier, Dunn, \& Dunn, 2019; Clark \& Malecki, 2019; Schmidt, Fleckenstein, Retelsdorf, Eskreis-Winkler, \& Möller, 2017).

General grit as well as academic grit scores are positively related to life satisfaction (Credé et al., 2017; Clark \& Malecki, 2019; Vainio, \& Daukantaite, 2015). Life satisfaction demonstrates a higher correlation with the perseverance of effort, than with the consistency of interests' scores (Credé et al., 2017). The relationship between grit and different aspects of well-being is partially mediated by a sense of coherence, on the one hand, and authenticity, on the other hand (Vainio, \& Daukantaitè, 2015). People experiencing psychological well-being (PWB) focus on a personal growth, they seek for a purpose in life, which might require motivation to pursue long-term goals - characteristic of the gritty individuals (Ryff \& Singer, 2008; Vainio, \& Daukantaitè, 2015) who seek happiness through engagement and meaning, but not through pleasure (Von Culin, Tsukayama, \& Duckworth, 2014)

Although the debate about the predictive validity of grit in explaining various outcomes over and above intelligence or some personality traits is ongoing, there are several instruments developed to measure grit; a 12-item Original Grit Scale (Grit-O; Duckworth et al., 2007) and an eight-item Short Grit Scale (GritS; Duckworth \& Quinn, 2009) provide domain general scores, while development of the domain specific measures of grit are in the spotlight (i.e. Cormier et al., 2019). These instruments are translated and validated in different countries in Europe and Asia (i.e. Li, Zhao, Kong, Du, Yang, \& Wang, 2016; Schmidt, Fleckenstein, Retelsdorf, Eskreis-Winkler, \& Moller, 2017) and support the higher-order factor structure of the Grit Scale.

\section{Present research}

The aim of the research is to examine the psychometric properties of the Georgian translation of the 12-item Original Grit Scale (Grit-O; Duckworth et al., 2007). The 12 item Grit Scale provides two different factors assessing the consistency of interests ("My interests change from year to year"), on the one hand, and perseverance of effort ("Setbacks don't discourage me"), on the other hand. The items are rated on a 5-point Likert-like scale from 1 not at all like me to 5 very much like me. The psychometric properties of the Georgian version of the Grit Scale, specifically, the factor structure, reliability and the relations with other constructs such as big five personality traits, creative achievements, and psychological well-being are examined in the study.

\subsection{Method}

\subsubsection{Participants}

The data collection was based on the three independent samples. As the presented results, depending on the relationships with variables under examination, involve either one or two samples, we report only the total sample size, mean age, and reliability coefficients (Cronbach's alphas) for each of the instruments. Altogether, 431 volunteers ( 241 females) participated in the study (aged from 17 to 66). No compensation has been offered. Participants gave their informed consent and had the possibility to drop out at any time.

\subsubsection{Instruments}

The Grit Scale. Prior to the present study, two experts prepared independent translations of the Grit Scale. After discussion, the two translated versions were combined to create the first Georgian version of the Grit Scale (G-Grit). Next, the questionnaire was back-translated to check whether the content of items matched the original content. Next, an initial administration of the test was conducted $(\mathrm{N}=30)$ to assess item coherence, as a result of which, several items have been modified. Personality traits. Ten-Item Personality Inventory (TIPI; Gosling, Rentfrow, \& Swann, 2003) was used to assess big five personality traits of openness, conscientiousness, extraversion, neuroticism, and agreeableness. Participants rated 10 items on a 7-point Likerttype scale from 1 (disagree strongly) to 7 (agree strongly) based on their degree of agreement with each item. The instrument was translated and validated in the framework of the unpublished research report (Sordia \& Martskvishvili, 2019).

Psychological well-being. Psychological well-being was measured by the Psychological Well-Being Scale (PWB; Diener, Wirtz, Biaswas-Diner, Tov, Kim-Prieto, Choi, \& Oishi, 2009) which consists of eight items describing important aspects of human functioning (i.e. "I lead a purposeful and meaningful life"). Each item is rated on a 7-point Likert type scale from 1 Strongly disagree to 7 Strongly agree. The inventory provides one general score of psychological well-being. The instrument was translated and validated in the framework of the unpublished research report (Martskvishvili, 2015).

Creative activities and achievements. Creative activities and achievements were assessed by the Georgian version (Martskvishvili \& Sordia, 2019) of the Inventory of Creative Activities and Achievements (ICAA; Diedrich, Jauk, Silvia, Gredlein \& Neubauer, 2017), which provides creative activities and achievement scores for eight different domains (literature, 
music, arts and crafts, creative cooking, sport, visual art, performing art and science and engineering). The creative activity scale consists of six items per domain and asks how frequently a certain activity has been performed in the past 10 years (i.e. "wrote a piece of music" or "wrote a blog entry"). Answers are given on 5 -point Likert-type scale $(0=$ never; $1=1-2$ times; $2=$ $3-5$ times; $3=6-10$ times; $4=$ more than 10 times). The creative achievement scale assesses past 10 years' achievements for eight domains on the 11 levels of attainment - ranging from I have never been engaged in this domain to I have already sold some work in this domain. The ICAA provides the domain-specific scores as well as the domain-general scores for creative achievements.

Table 1. Means, standard deviations, and reliability coefficients of the measures

\begin{tabular}{|c|c|c|c|c|c|}
\hline & $N$ & Item $N$ & Chronbach's $\alpha$ & $M$ & $S D$ \\
\hline \multicolumn{6}{|l|}{ TIPI } \\
\hline Openness & 98 & 2 & .43 & 10.37 & 2.76 \\
\hline Conscientiousness & 98 & 2 & .57 & 10.69 & 2.88 \\
\hline Extraversion & 98 & 2 & .64 & 8.38 & 3.57 \\
\hline Agreeableness & 98 & 2 & .28 & 11.11 & 2.38 \\
\hline Neuroticism & 98 & 2 & .65 & 8.37 & 3.45 \\
\hline Creative achievements & 254 & 88 & .84 & 5.81 & 5.22 \\
\hline Creative activities & 254 & 48 & .95 & 1.54 & 0.69 \\
\hline Psychological well-being & 248 & 8 & .82 & 43.30 & 7.14 \\
\hline
\end{tabular}

Note. TIPI = Ten-Item Personality Inventory

\section{Results}

\subsection{Factor structure}

The CFA for the two-dimensional higher-order model did not fit the data sufficiently: $\chi 2(53)=209.65, \mathrm{CFI}=.90, \mathrm{RMSEA}=.08$. Due to high modification indices, we allowed the correlation between item residuals of three items (Item 1, 6, and Item 8). As the items were similar, these modifications seemed to be theoretically sound. The modified two-dimensional second-order model of grit appeared to fit the data well $[\chi 2(25, \mathrm{~N}=431)=$ $133,525, \mathrm{p}<.001]$. The comparative fit index $(\mathrm{CFI})=.95$, the Tucker-Lewis fit index $(\mathrm{TLI})=.93$, and the RMSEA $=.06$. The two sub-scales - Consistency of Interest (CI), and Perseverance of Effort (PE) were first order latent factors loaded on the first order factor. The factor structure and factor interrelations are presented in Figure 1 and Table 2, respectively.

Figure 1. Standardized factor loadings for the model

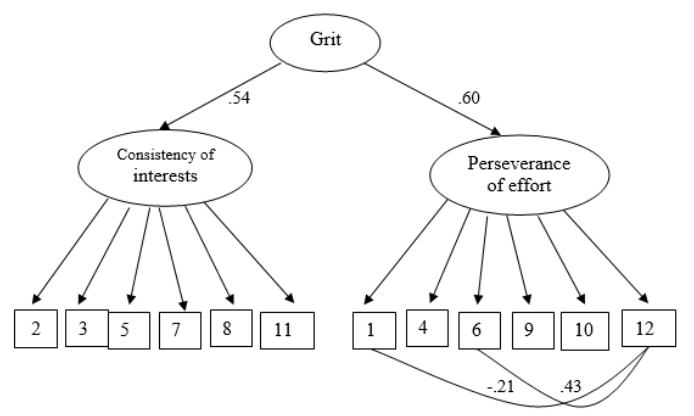

\subsection{Descriptive statistics and internal consistencies}

Minimum, maximum, skewness, and kurtosis of the two factors, and the global grit score are reported in Table 2. Also, mean and standard deviations are provided for men and women, indicating that there are no significant gender differences in terms of grit. The global construct of grit as well as consistency of interest, and perseverance of effort display acceptable reliabilities. 
Table 2. Descriptive statistics, internal consistencies and inter correlations of the Grit $\operatorname{Scale}(\mathrm{N}=431)$

\begin{tabular}{|c|c|c|c|c|c|c|c|c|c|c|c|c|c|}
\hline & \multirow[t]{2}{*}{$M$} & \multirow[t]{2}{*}{$S D$} & \multirow[t]{2}{*}{ Chronbach's $\alpha$} & \multirow[t]{2}{*}{ Item $N$} & \multirow[t]{2}{*}{ Skewness } & \multirow[t]{2}{*}{ Kurtosis } & \multicolumn{2}{|c|}{ Woman } & \multicolumn{2}{|c|}{ Man } & \multirow[b]{2}{*}{$t$} & \multirow[b]{2}{*}{ CI } & \multirow[b]{2}{*}{$\mathrm{PE}$} \\
\hline & & & & & & & $M$ & $S D$ & $M$ & $S D$ & & & \\
\hline CI & 3.10 & .90 & .79 & 6 & -.09 & -.78 & 3.08 & .89 & 3.11 & .91 & .36 & - & \\
\hline PE & 3.68 & .80 & .80 & 6 & -.47 & -.04 & 3.70 & .80 & 3.65 & .80 & -.68 & $.25 * *$ & - \\
\hline Grit & 3.39 & .67 & .80 & 12 & -.09 & -.41 & 3.39 & .65 & 3.38 & .70 & -.16 & $.82 * *$ & $.76^{* *}$ \\
\hline
\end{tabular}

\subsection{Construct validity}

Correlations with other constructs are provided in Table 3. Global score of grit as well as its both factors are positively correlated with big five traits of conscientiousness. The relationship between psychological well-being and grit is positive and significant. Creative achievements are positively related with the overall score of grit as well as its factor of persistence of effort.

Table 3. Correlation matrix

\begin{tabular}{|c|c|c|c|}
\hline & $\mathrm{CI}$ & $\mathrm{PE}$ & Grit \\
\hline PWB & $.18 * *$ & $.56 * *$ & $.43 * *$ \\
\hline Creative achievements & .04 & $.18^{* *}$ & $.13^{*}$ \\
\hline Creative activities & .06 & $.17 *$ & $.14 *$ \\
\hline \multicolumn{4}{|l|}{ TIPI } \\
\hline Neuroticism & $-.35 * *$ & -.17 & $-.33 * *$ \\
\hline Conscientiousness & $.23 *$ & $.37 * *$ & $.36 * *$ \\
\hline Openness & .04 & $.24 *$ & .17 \\
\hline Agreeableness & .05 & .04 & .06 \\
\hline Extraversion & .07 & $.29 * *$ & $.21 *$ \\
\hline \multicolumn{4}{|c|}{$\begin{array}{l}\text { Note. }{ }^{*} \mathrm{p}<.05 * * \mathrm{p}<.01 ; \mathrm{PWB}=\text { psychological well-being; CI } \\
\text { interests; } \mathrm{PE}=\text { perseverance of }\end{array}$} \\
\hline
\end{tabular}

\section{Discussion}

The present study aimed to examine the psychometric properties of the Georgian translation of the Grit Scale (Duckworth et al., 2007). Confirmatory factor analyses supported the two-factor structure of grit; consistency of interest and perseverance of effort both were the first-order factors. The result is consistent with the theoretical framework of the concept, where grit is considered as a higher-order construct with two lower order facets (Duckworth et al., 2007; Duchworth et al., 2009). Inter-factor correlation of the scale is similar to the results of the previous studies (i.e. Clark \& Malecki, 2019) indicating that factors of the Grit Scale; consistency of interests, on the one hand, and perseverance of effort, on the other hand, are interrelated but distinct constructs having different correlates (Credé et al., 2017).

Unlike the meta-analysis (Credé et al., 2017) indicating the very strong correlation between conscientiousness and grit, in the present study, the relationship between conscientiousness and consistency of interests as well as the perseverance of effort scales are positive but moderate. As the big five personality traits are measured by the ten-item personality inventory and conscientiousness is assessed by the only two items, it could be speculated that all the facets of the conscientiousness are not captured by the inventory used in the present study. Those facets, namely, self-control can strengthen the correlation between grit and conscientiousness.

Both factors of grit are positively related to psychological wellbeing. The relationship between psychological well-being and perseverance of effort is much stronger than the relationship between psychological well-being and consistency of interests as demonstrated in the previous studies (i.e. Credé et al., 2017; Vainio, \& Daukantaitè, 2015).

The relationship between grit and educational achievements is thoroughly examined topic, where grit is considered as a significant predictor of performance and success (Credé et al., 2017; Duckworth, Kirby, Tsukayama, Berstein, \& Ericsson, 2011). In our study grit was examined as a correlate of creative performance measured by creative activities and achievements. According to the results only the perseverance of effort was related to creative activities as well as creative achievements. Creative activities and achievements are distinct from creative ability and consist of everyday creative activities and real-life creative accomplishments acknowledged by others (Eysenck, 1995; Wallach \& Wing, 1969; Diedrich et al., 2017). Creative achievements are predicted by intelligence, creative activities, 
emotionality, novelty, and openness to experience (Batey, Furnham, \& Safiullina, 2010; Jauk, Benedek, \& Neubauer, 2013; Runco, Millar, Acar, \& Cramond, 2010; Sordia, Martskvishvili, \& Neubauer, in press; Torrance, 1969; Torrance, 2003; Wallach $\&$ Wing, 1969). For attaining creative achievements a willingness to overcome obstacles (Sternberg \& Lubart, 1991), an intention of being creative (Nickerson, 1985), and to understand and influence other people's emotions are necessary (Sordia et al., in press). Thus, the way to creative achievements might be full of obstacles and gaining creative accomplishments can be related to the individual's tendency to follow personally meaningful goals and overcome any kind of obstacles or setbacks in the way to the goals.

\section{Limitation and conclusion}

The main limitation of the present study is related to the measurement method of personality traits. We assess big five personality traits with the measure that did not capture all aspects of the traits thoroughly. This could have affected the results of the study. Also, It would be reasonable to assess divergent validity of grit in predicting creative activities and achievements, as well as psychological well-being over and above personality traits. Notwithstanding these restrictions, psychometric properties of the Georgian translation of the Grit Scale are satisfactory. Confirmatory factor analysis confirms two-dimensional secondorder factor structure of the Grit Scale. In sum, because of its factor structure, the internal consistencies and validities regarding other constructs, the Georgian version of The Grit Scale seems well suited for future research purposes.

\section{References}

1. Batey, M., Furnham, A., \& Safiullina, X. (2010). Intelligence, General Knowledge and Personality as predictors of creativity. Learning and Individual Differences, 20(5), $532 \quad$ - 535. Doi: 10.1016/j.lindif.2010.04008

2. Butz, N. T., Hanson, S., Schultz, P. L., \& Warzynski, M. M. (2018). Beyond the Big Five: does grit influence the entrepreneurial intent of university students in the US? Journal of Global Entrepreneurship Research, 8(1). doi:10.1186/s40497-018-0100-Z

3. Clark, K. N., \& Malecki. Ch. K. (2019). Academic Grit Scale: Psychometric properties and associations with achievement and life satisfaction. Journal of School Psychology, 72, 49-66. Doi:10.1016/j.jsp.2018.12.001

4. Cormier, D. L., Dunn, J. G. H., \& Dunn, J. C. (2019). Examining the domain specificity of grit. Personality and Individual Differences, 139, 349-354. Doi:10.1016/j.paid.2018.11.026
5. Credé, M., Tynan, M. C., \& Harms, P. D. (2017). Much Ado About Grit: A Meta-Analytic Synthesis of the Grit Literature. Journal of Personality and Social Psychology, 113, 492-511. Doi: 10.1037/pspp0000102 6. Diedrich, J., Jauk, E., Silvia, P. J., Gredlein, J. M., Neubauer, A. C., \& Benedek, M. (2017). Assessment of real-life Creativity: The Inventory of Creative Activities and Achievements (ICAA). Psychology of Aesthetics, Creativity, and the Arts. Advance online publication. doi: $10.1037 / \mathrm{aca} 0000137$

7. Duckworth, A. L., \& Quinn, P. D. (2009). Development and Validation of the Short Grit Scale (GritS). Journal of Personality Assessment, 91(2), 166-174. doi:10.1080/00223890802634290

8. Duckworth, A. L., \& Gross, J. J. (2014). Self-control and grit: Related but separable determinants of success. Current Directions in Psychological Science, 23, 319-325. Doi:10.1177/0963721414541462.

9. Duckworth, A. L., Kirby, T. A., Tsukayama, E., Berstein, H., \& Ericsson, K. A. (2011). Deliberate practice spells success: Why grittier competitors triumph at the national spelling bee. Social Psychological \& Personality Science, 2, 174-181. doi:10.1177/1948550610385872 10. Duckworth, A. L., Peterson, C., Matthews, M. D., \& Kelly, D. R. (2007). Grit: Perseverance and passion for long-term goals. Journal of Personality and Social Psychology, 92, 1087-1101. doi: 10.1037/00223514.92.6.1087

11. Eskreis-winkler L., Duckworth A., Shulman E., \& Beal S. (2014) The grit effect: predicting retention in the military, the workplace, school and marriage. Frontiers in Psychology 5. doi:10.3389/fpsyg.2014.00036

12. Eysenck, H. J. (1995). Genius: The natural history of creativity. New York: Cambridge University Press.

13. Gosling, S. D., Rentfrow, P. J., \& Swann, W. B. (2003). A very brief measure of the Big-Five personality domains. Journal of Research in Personality, 37(6), 504528. doi:10.1016/s0092-6566(03)00046-1

14. Jauk, E., Benedek, M., \& Neubauer, A.C. (2013). The road to creative achievement: A latent variable model of ability and personality predictors. European Journal of Personality, 28(1), 95-105. Doi: 10.1002/per.1941

15. Larkin, P., O'Connor, D., \& Williams, A. M. (2015). Does Grit Influence Sport-Specific Engagement and Perceptual-Cognitive Expertise in Elite Youth Soccer? Journal of Applied Sport Psychology, Doi: 10.1080/10413200.2015.1085922

16. Li, J., Zhao, Y., Kong, F., Du, S., Yang, S., \& Wang, S. (2016). Psychometric Assessment of the Short Grit Scale Among Chinese Adolescents. Journal of Psychoeducational 
Assessment,

$36(3)$,

$291-296$

Doi: $10.1177 / 0734282916674858$

17. MacCann, C., \& Roberts, R. D. (2010). Do time management, grit, and self-control relate to academic achievement independently of conscientiousness? In R. Hicks (Ed.), Personality and individual differences: Current directions (pp. 79-90). Queensland, Australia: Australian Academic Press.

18. Martskvishvili, Kh. (2015). [The role of intelligence, emotion-related personality aspects and self-actualization in creativity]. Unpublished raw data.

19. Nickerson, R. S. (1985). Enhancing creativity. In R. J. Sternberg (Ed.), The nature of creativity (pp. 11-38). Cambridge, UK: Cambridge University Press.

20. Rimfeld, K., Kovas, Y., Dale, P. S., \& Plomin, R. (2016). True grit and genetics: Predicting academic achievement from personality. Journal of Personality and Social Psychology, 111(5), 780-789. Doi:10.1037/pspp0000089

21. Runco, M. A., Millar, G., Acar, S., \& Cramond, B. (2010). Torrance Tests of Creative Thinking as Predictors of Personal and Public Achievement: A Fifty-Year FollowUp. Creativity Research Journal, 22(4), 361-368. Doi:10.1080/10400419.2010.523393

22. Schmidt, F. T. C., Fleckenstein, J., Retelsdorf, J., Eskreis-Winkler, L., \& Moller, J. (2017). Measuring Grit: A German validation and a domain-specific approach to grit. European Journal of Psychological Assessment. Doi: 10.1027/1015-5759/a000407

23. Schmidt, F. T. C., Fleckenstein, J., Retelsdorf, J., Eskreis-Winkler, L., \& Möller, J. (2017). Measuring grit: A German validation and a domain-specific approach to grit. European Journal of Psychological Assessment. Doi:10.1027/1015- 5759/a000407

24. Sordia, N., \& Martskvishvili, Kh. (2019). [From creative potential to creative achievements: The role of culture and personality]. Unpublished research report.

25. Sordia, N., \& Martskvishvili, Kh. (2019). [Psychometric properties of the Georgian version of the creative activities and achievements inventory] manuscript in preparation.

26. Sordia, N., Martskvishvili, Kh., \& Neubauer, A.C. (In press). From creative potential to creative achievements: Do emotional traits foster creativity? Swees Journal of Psychology.

27. Sternberg, R. J., \& Lubart, T. I. (1991). An investment theory of creativity and its development. Human Development, 34, 1-31. Soi: 10.1159/000277029

28. Vainio, M. M., \& Daukantaite, D. (2015). Grit and Different Aspects of Well-Being: Direct and Indirect
Relationships via Sense of Coherence and Authenticity. Journal of Happiness Studies, 17(5), 2119-2147. Doi:10.1007/s10902-015-9688-7

29. Von Culin, K. R., Tsukayama, E., \& Duckworth, A. L. (2014). Unpacking grit: Motivational correlates of perseverance and passion for long-term goals. The Journal of Positive Psychology, 9(4), 1-7. doi:10. 1080/17439760.2014.898320.

30. Wallach, M. A., \& Wing, C. W., Jr. (1969) The Talented Student: A Validation of the CreativityIntelligence Distinction. New York: Holt, Rinehart and Winston. 